\title{
Destination management and sustainable tourism deve- lopment through the common lens of the Commons
}

\author{
João Romão ${ }^{1}$, Mayumi Okada ${ }^{2}$, Kazuo Machino $^{3}$, Peter Nijkamp ${ }^{4}$ \\ ${ }^{1}$ Yasuda Women's University, Hiroshima, Japan \\ ${ }^{2}$ Hokkaido University, Sapporo, Japan \\ ${ }^{3}$ Hokkaido Musashi Women's Junior College, Sapporo, Japan \\ ${ }^{4}$ AI Cuza University, Iasi, Romania
}

Received: 31 October 2019/Accepted: 18 January 2021

\begin{abstract}
This study combines three interconnected streams in tourism literature: analysis of the utilisation of common pool resources (CPR) in tourism, studies on sustainable tourism development and theoretical contributions to the articulation of roles, missions and strategies of a destination management organisation (DMO). Starting from an integrative literature review, our aim is to explore the symbiotic relationships between these approaches in order to design a conceptual framework for opening new research opportunities. The operational application of such a conceptual model depends on the resources of each destination, the type of tourism dynamics observed, the specific stakeholders involved and the power balance between them. Our objective is to define and to discuss the critical conditions for the integration of sustainable development principles into the strategic role of a DMO through the management of CPR via participatory processes of destination management. An exploratory illustration of this framework for the rural destination of Kushiro-Akan (Hokkaido, Japan) is presented. Policy and managerial implications as well as the needs for further research are discussed.
\end{abstract}

Key words: common pool resources, destination management organisation (DMO), sustainable development, participatory governance

\section{Introduction}

Many of the local resources attracting tourists to a destination can be framed as "Common Pool Resources" (CPR), as defined by Ostrom (2008). Although most approaches analysing the relationship between tourism and the preservation as well as appropriation of benefits related to the utilisation of these resources focus on environmental assets (Holden 2005, Moore, Rodger 2010, Pirotta, Lusseau 2015, Heenehan et al. 2015), several authors enlarge the scope of the analysis of CPR in tourism by considering other resources contributing to destination attractiveness (Briassoulis 2002, Bimonte 2008). Adopting a broad perspective, Briassoulis (2015, p. 92) defines the "tourism commons" as "the collection of natural, manmade and socio-cultural resources of host areas and their surrounding regions that are purposefully or inadvertently used in common by tourist and non-tourist activities".

Thus, the adequate management of common resources - both in terms of their protection and also considering the aspects of social justice related to their utilisation appears crucial for the sustainable development of a destination. In the case of tourism, as 
stressed by Butler (1999) or Sharpley (2009), such an approach to sustainability implies a careful use of territorial resources (or the protection and preservation of CPR, as proposed in the literature on the Commons), along with contributions to the improvement of the host communities' socio-economic conditions (or an adequate management of the appropriation of benefits arising from the utilisation of those resources, as formulated in the conceptual approaches to the management of CPR).

Considering the wide range of stakeholders involved in the provision of tourism services as well as the different implications of tourism dynamics for diverse groups within the host communities and their different perceptions regarding the value, utilisation or importance of CPR preservation, participatory processes of tourism management and planning appear to be crucial for sustainable tourism development. In this sense, Briassoulis (2015, p. 92) proposes the concept of "adaptive tourism governance", which is defined as a "multi-level, participatory process of sustainably managing collective affairs under uncertainty in complex tourism socio-ecological systems".

Different streams of literature offer relevant insights for the analysis of these problems: Dietz et al. (2003) or Ostrom (2008) propose this type of participatory governance for the general case of CPR; Briassoulis (2002) or Holden (2005) focus on the specific case of CPR for tourism; institutions like UNESCO (2013) suggest similar processes of stakeholder involvement for the management of cultural heritage; UNWTO (2003, 2007) suggests that DMO should involve all local relevant stakeholders to guarantee sustainable tourism development. In their systematic and comprehensive analysis of multi-stakeholder involvement in tourism management, Waligo et al. (2013) point out the insufficient community participation as a crucial reason for the lack of achievement of sustainable development goals within processes of tourism development. However, this involvement of local stakeholders implies a strong perception of the significance of these mechanisms and institutions (Hall 2019).

Inspired by these contributions, this work aims to develop a symbiotic integration of three different types of interlinked theoretical approaches: the analysis of the utilisation of CPR for tourism purposes; the studies on sustainable tourism development; and the analytical contributions to the definitions of roles, missions and strategies of a destination management organisation (DMO). By focusing on the importance of community-based CPR management, we develop a conceptual approach to the integration of sustainable development principles into the strategic role of a DMO, aiming at identifying and discussing the critical conditions for its implementation. The specific institutional focus on DMOs reflects the suggestion by UNWTO (2007) to assume sustainable development as the main objective of contemporary destination management organisations, while ensuring that potentially implemented collaborative processes correspond to a significant level of decision-making.

By defining and discussing such critical conditions, our framework aims at opening new opportunities for research as well as the application of such a conceptualisation, which depends on the resources of each destination, the type of tourism dynamics observed, the specific stakeholders involved and, among other factors, the power balance between them. As an example, we present an exploratory illustration of the Kushiro-Akan rural destination (Hokkaido, Japan) case, following two extensive studies previously undertaken in this area (Romão et al. 2017, 2018). The concepts and theoretical contributions underlying this analysis are presented in Section 2, considering the concepts of CPR in tourism (2.1), sustainable tourism development (2.2) and DMO (2.3). The integration and synthesis of these approaches are presented in Section 3, proposing a conceptual framework model for destination management. Section 4 offers an illustrative application of this model to the Kushiro-Akan destination, and Section 5 concludes the paper with a discussion of the main results, critical factors for the implementation of such a governance model as well as the limitations of the study and possibilities for further research.

REGION: Volume 8, Number 1, 2021 
Table 1: Common, destination management and sustainable development

\begin{tabular}{cccc}
\hline \multicolumn{3}{c}{ Common Pool Resources } \\
\hline \multirow{2}{*}{ Problems } & $\begin{array}{c}\text { Overutilisation and } \\
\text { lack of protection }\end{array}$ & Appropriation of & Destination \\
Solutions & bustainable & Economits growth & Sustainable \\
& long-term utilisation & and social justice & development \\
\hline
\end{tabular}

\section{Sustainable development and destination management through the common lens of the Commons}

The methodology for this analysis incorporates the principles of an integrative literature review (Torraco 2005), combining three different streams of theoretical contributions within a systematic scoping review (Rasoolimanesh et al. 2020) and focusing the literature review on a specific research question, rather than offering a detailed perspective. The novelty of this approach lies in the systematisation as well as the synthesis of different theoretical contributions converging to the question of common resources management in tourism destinations (Section 2). This leads to the definition of a conceptual model for the implementation of institutional solutions addressing this problem (Section 3) and is illustrated by the presentation of an exploratory example in a rural destination in Japan, with diverse resources that can be broadly classified as CPR, where a DMO has been recently implemented (Section 4 ).

Considering the characteristics of CPR, the problems related to their utilisation in tourism are regarded as challenges for destination management (as represented in the first row of Table 1), whose solutions may contribute to a process of sustainable development (as mentioned in the second row). Thus, the achievement of significant results in terms of the three pillars of sustainable development depends on an adequate management of common resources, which implies the implementation of participatory management processes. The particular aspects of CPR management in the context of tourism development are discussed in Section 2.1, while a more specific focus on recommendations, guidelines and proposals for the utilisation of natural as well as cultural resources is presented in Section 2.2. We conclude by discussing the potential role of DMOs as potential leaders of such a participatory process of CPR management, considering their institutional legitimacy in promoting and coordinating tourism activities, along with the recommendations from UNWTO (2007) regarding their potential leadership within sustainable tourism development processes. The main ideas arising from these different approaches are presented in Table 2, at the end of this Section.

\subsection{Common Pool Resources}

CPR are characterised by "subtractability" (rivalry among potential users, implying that CPR utilisation by one user may exclude the possibility of their utilisation by others) and "non-excludability" (it is difficult or impossible to limit the access to the resource). Generally, these resources are indivisible, and it is not easy to define their boundaries. Thus, it is difficult to define legitimate users or to exclude others. CPR can be subject to different property regimes (private, public or common), which can change over time. These characteristics are assumed in most of the studies on this topic (Holden 2005).

The levels of "excludability" and "rivalry" may differ for different types of goods. In a pure sense, CPR are characterised by rivalry and non-exclusion, but it is possible to change these conditions: a private beach or the limitation to a certain number of users of natural parks or museums may be seen as generating "exclusion", while eliminating or reducing "rivalry". Musgrave, Musgrave (1973) or Ostrom, Ostrom (1977) define this regime as a "club", implying a certain form of privatisation of resource utilization, while facilitating its management and preservation. For other resources (like air, public security or national defence), there is no "excludability" - they can be utilized by an unlimited number of users and can be classified as "public goods". For our purposes, all 
these types of goods are taken into account, once they are no longer a subject to market transactions or regulated by market forces. Moreover, all of them raise the question of the appropriation of benefits, for the tourism sector tends to be highly dominated by large international companies operating in the transportation and accommodation services. The emphasis on the commons is due to the fact that these resources tend to get less attention than public goods in literature on economics and management.

Examples of CPR include natural resources (atmosphere, water, ecosystems, fisheries, forests or wildlife), infrastructure built for collective utilisation (irrigation systems, water distribution and treatment, streets, transportation systems, ports) and immaterial assets shared by a broad community of users (cyberspace, electro-magnetic spectrum, genetic data, traditions, language, knowledge or other creative assets). Once they are not subject to market transactions, their economic value is difficult to measure, even though they are often a source of economic externalities, contributing to the creation and appropriation of value (Scott 2017).

When supporting different recreational or educational activities, along with hospitality services, natural landscapes, monuments or architectural landmarks can also be seen as good tourism-related examples of CPR. In fact, many resources attracting tourists to a destination (culture, nature, landscapes, lifestyles, etc.) can be framed as CPR and can be identified in tourism destinations. Moreover, other resources, facilities or infrastructure with common characteristics can be impacted by tourism dynamics, as observed in detail by Colomb, Navy (2017): local transportation networks; public spaces; public or private services shared between tourists and residents; traditional lifestyles and common forms of life in specific neighbourhoods; or even the collective supply of housing, which is normally subject to planning processes at the local level, having recently become an especially important problem in cities with high tourism demand and the transformation of residential places into tourism accommodation facilities.

Thus, the exploitation of positive externalities related to the existence of common resources may also imply the emergence of negative externalities, with implications for the living conditions of residents. Consequently, diverse types of users have different perceptions about the value of CPR, depending on how they are affected by the externalities (along with aspects related to information, education or cultural values). In the case of tourism, the economic valuation of CPR is also made by users not belonging to the local community, being highly dependent on their individual characteristics (Briassoulis 2002).

Different types of problems related to the utilisation of CPR are identified in the literature (e.g, Briassoulis 2002, Coronado 2014, Nahrath, Bréthaut 2016). On the demand side, the "free-riding" (over-utilisation and appropriation of resources by a limited number of users, eventually leading to the exclusion of others) can lead to resources' degradation or elimination as a consequence of a cumulative non-planned utilisation. On the supply side, the lack of resource preservation as well as of protection may arise (as none of the users has individual responsibility to do it), along with a potentially unequal appropriation of benefits (although the CPR are available for the whole community or are even produced collectively, the appropriation of benefits is private and can be different for various types of users). In fact, transportation and accommodation companies generally get large benefits from the attractiveness of CPR in a destination, not necessarily contributing to their improvement or preservation, while large parts of the local population can be excluded from the benefits of tourism or affected by the presence of tourists and the related negative externalities.

Considering the difficulties and problems with the utilisation, management, preservation, economic valuation and the appropriation of benefits related to these resources (along with the different types of stakeholders using the CPR, with different perceptions about their value), some authors propose general principles for their management. Dietz et al. (2003) summarise these principles, which are depicted in the column titled "CPR" in Table 2 (definition of boundaries; equivalence between benefits of utilisation and preservation costs; implementation of collective-choice arrangements; mobilisation of local communities; and monitoring processes based on quantitative indicators). Generally, these principles (and similar approaches broadly inspired by different formulations proposed by Ostrom, Ostrom 1977, Ostrom 2005, 2008) focus on the utilisation and management of CPR by 
communities with "permanent" members. However, in the case of tourism, resources are also used by temporary visitors (the tourists), imposing new challenges for CPR management.

\subsection{Management of natural and cultural heritage as commons and tourism resources}

Natural resources have attracted travellers for thousands of years, as documented by Graburn (1995) mentioning tourist visits to rural areas of Japan, to enjoy Japanese baths (onsen), at least during the last 3.000 years. Similar movements were observed in the Roman Empire, when thermal baths motivated people to travel, being a central element of daily life. Different types of nature-based tourism emerged since then, including trips to coastal areas (leading to the development of massive forms of tourism in many places), winter sports in mountain areas or, more recently, rural tourism or different types of ecotourism related to recreational and educational activities.

The problematic utilisation of natural resources in tourism has led to different analyses, as written by Meinecke (1929), ORRRC (1962) or Wagar (1964). This type of studies had a strong impulse following the publication of "Our Common Future" (World Commission on Environment and Development 1987) and the generalised acceptance of the concept of sustainable development, which was rather quickly adopted within tourism studies and policy guidelines (Sharpley 2009). In the subsequent years, the importance of protecting these resources (e.g., by defining limits for their utilisation according to their carrying capacity) or their role within strategic processes of destination differentiation, have been widely analysed (Butler 1999, Buhalis 1999, Hassan 2000, Miller, Twining-Ward 2005, Williams, Ponsford 2009). The problems related to climate change reinforced the importance of this discussion (Weaver 2011). Douglas (2014) stresses that the commercialisation of environmental features within tourism markets often raises questions related to excessive use, degradation or destruction, while Coronado (2014) or Nahrath, Bréthaut (2016) focus on the interactions between visitors and host communities.

Heenehan et al. (2015) and Moore, Rodger (2010) use the CPR approach in order to propose a framework model for participatory resource management in places where tourism plays a prominent role, which are especially relevant in the context of our work. Based on the systematisation of principles for CPR management proposed by Ostrom (2005), Heenehan et al. (2015) consider attributes related to resources, users and the interactions between them. This includes the identification of the spatial extent of resources and their predictable use (related to their importance and cost), in order to promote their improvement and monitoring through specific indicators. Participatory management should be based on autonomy, trust and reciprocity, taking previous experiences into consideration. Following a conceptual approach proposed by Agrawal (2001, 2003), Moore, Rodger (2010) discuss the enabling conditions characterising resources, users and the relations between them, taking into account institutional arrangements and their interaction with the resource system, along with aspects related to the external environment. These aspects are framed in Table 2 (columns titled "Enabling conditions" and "Attributes").

Just as natural resources, cultural heritage has attracted visitors for thousands of years. A relevant ancient example is the religious motivation for travel (pilgrimage), but many other material (monuments, architecture, artefacts, etc.) or immaterial (lifestyles, events, local knowledge, etc.) cultural assets have had a significant impact on motivations to travel. The impressive contemporary dynamics observed in urban tourism (UNWTO 2012) are also clearly linked to this kind of motivation (Mazanec 2010, Romão et al. 2015). However, the utilisation of cultural assets in tourism may raise long-term problems, which can be framed within the concept of sustainability. Being subject to different processes of commodification and marketing strategies, the preservation of the integrity, meaning and authenticity of these cultural values requires permanent efforts of protection and regulation, as suggested by different authors (Cohen 1988, Poria et al. 2003, Chambers 2009, Fusco Girard, Nijkamp 2009) and policy institutions (UNWTO 2003, ICOMOS 2008a,b, OECD 2009). Romão (2018) offers a detailed discussion of these aspects.

The policy recommendations proposed by ICOMOS (1999) address the utilisation of common cultural resources in tourism, based on a broad definition of heritage, 
including both natural and cultural aspects: "landscapes, historic places, sites and built environments, as well as bio-diversity, collections, past and continuing cultural practices, knowledge and living experiences. It records and expresses the long processes of historic development, forming the essence of diverse national, regional, indigenous and local identities and is an integral part of modern life". It is assumed that "heritage-based tourism must offer relevant socio-economic benefits for the local communities, while requiring their active participation in the management of heritage resources and tourism dynamics at the local level". This broad focus on landscapes, combining the protection and valorisation of both cultural and natural assets, has been identified in collaborative processes of tourism management involving local communities in Australia (Tolkach et al. 2016) or New Zealand (Grafton 2000), also reinforcing the participation of indigenous communities - even though this did not imply that all the conflicts could be solved or eliminated, as observed by Tribe (2008).

ICOMOS (1999) also defines guidelines for the management of heritage (embedded in the column titled "cultural heritage - ICOMOS" in Table 2), considering the importance of public awareness, the dynamic relationship (and conflicting values) between heritage places and tourism, the need to create a worthwhile visitor experience, the importance of involving host and indigenous communities in the planning processes, the definition of responsible promotion programs, as well as the achievement of benefits for the local communities through job creation and valorisation of local products. Furthermore, when proposing a set of challenges to be addressed while defining a long-term strategy for heritage tourism, UNWTO (2003) also acknowledged the importance of heritage for tourism development and the implications on the implementation of participatory management processes. These principles (integrated into the column "cultural heritage - UNWTO" in Table 2) include: understanding of links between tourism and heritage, definition of heritage-based tourism products, preservation of authenticity, definition of limits of acceptable change, adequate balance between education and entertainment, identification of relevant stakeholders, creation of partnerships, and implementation of participatory mechanisms.

Despite all the recommendations for implementing participatory processes of planning and management, the achievements are far from satisfactory, as observed by Hall (2019), when stressing the importance of combining not only different interests and perspectives, but also diverse types of knowledge coexisting within local communities. These difficulties were also testified by Landorf (2009), when analysing plans for tourism development in World Heritage Sites in the United Kingdom, observing that, despite the existence of a longterm approach and a formal goal-oriented planning process, local communities could not be successfully involved in any of the cases. Furthermore, Coronado (2014) observed that conflicts of interests between different stakeholders involved in two tourism development projects in rural areas of Mexico could not be solved, leading to their commercial failure. Similarly, Jamal, Stronza (2009) identified difficulties when trying to combine traditional and scientific types of knowledge among stakeholders from local communities and international institutions in the management of natural parks in Colombia. Moreover, other economic problems arising from the lack of community involvement were recently observed by Seyfi et al. (2018) in a World Heritage Site in Iran or by Dragouni, Fouseki (2018) in Greece.

\subsection{Destination Management Organizations (DMO)}

Despite the persistence of conflicts between different interests and perspectives of diverse stakeholders, some rare examples of relatively successful participatory processes of tourism planning and management can be pointed out, like the cases observed in New Zealand (Grafton 2000) or Australia (Tolkach et al. 2016), where local institutional solutions were strongly supported and framed by national policies. Despite these scarce achievements, there is abundant literature on this topic, as exemplified by the early analysis performed by Bramwell, Sharman (1999), emphasising problems related to power imbalances within collaborative processes. More recently, the systematic review proposed by Fyall et al. (2012) identifies different dimensions and typologies for these collaborative processes, also emphasising their limitations and the need for further research. Our study focuses on 
collaborative processes of tourism planning and management within a DMO, in order to ensure the policy and institutional legitimacy - and thus the significance - of the network (as defined by Hall 2019).

Generally assuming tasks related to planning, marketing and management of tourism destinations, DMOs may be based on institutions that can integrate the management of CPR into the processes of strategic tourism development. However, it should be noticed that there is no universal definition of DMOs (Pike 2016): their missions, objectives, structures and names can be different, depending on the location. Pike (2016) offers a detailed historical overview of the evolution of DMOs since the end of the 19th century as well as an analysis of the limitations for their actions. Moreover, he points out that they cannot change the reputation or the geographic limits of their locations; they also do not necessarily control the number of visitors and its relation to carrying capacity and have limited (if any) contact with visitors as well as limited control over the attitudes of host communities. DMOs have no control over the different stakeholders' strategies and decisions related to product development, pricing or marketing approaches, as they do not control transportation services, infrastructure or the management of the natural environment and cultural heritage.

DMO are normally dependent on public institutions and/or large private companies, which can raise different types of problems. Public funding (subsidies, grants, provision of services, allocation of taxes, etc.) seems adequate to ensure a power balance between the stakeholders involved, but it implies a strong dependence on policy decisions not controllable by the tourism sector. Funding based on private contributions may be a source of power imbalance between the involved stakeholders, eventually creating a high dependence on a small group of large companies with a dominant position and resulting in difficulties when involving local communities without a direct benefit from tourism (Mason 2016). Considering the importance of a balanced representation of diverse groups with different interests and motivations, a strong share of public financing proves crucial.

DMO can be seen as a coordinator and facilitator of a common strategy, acting as a "coalition of different interests for working towards a common goal, ensuring the viability and integrity of their destination at present and for the future", as suggested by UNWTO (2007). They can operate at different territorial levels, with their actions potentially exerting cumulative impacts on the same destinations, thus implying a clear definition of tasks and complementarities between them. Destination coordination and management, along with the development and management of events and attractions, should be addressed at the local level.

Accordingly, our conceptual model for the integration of CPR management into processes of tourism development focuses on the local level of the destination, which seems more adequate for planning the utilisation of sensitive resources while taking different interests of the diverse stakeholders involved into account. It is assumed that the role of DMO has shifted over time from a promotion-oriented approach driven by short-term economic objectives to a contemporary holistic approach focused on long-term competitiveness, while taking into account the sustainable use of resources as well as the need to manage and solve the potential conflicts between different groups with diverse interests and motivations.

UNWTO (2007) proposes a broad set of guidelines (integrated into the column titled "DMO for SD" in Table 2) addressing the three pillars of sustainable development, which are in accordance with the concerns related to the management of CPR. Such a holistic approach to the role of DMO implies a long-term perspective for the competitiveness of a tourism destination, including the broad range of stakeholders involved in tourism development: policy and regulatory institutions (national and regional governments, economic development agencies, local authorities, authorities responsible for the management of natural parks or cultural facilities, etc.), private companies in different sectors (transport, attractions and events, accommodation, restaurants, leisure services, retail operators, different types of intermediaries, etc.) or different local organisations (local partnerships, business support agencies, education and training organisations, media, NGOs, or organised groups of residents). Involving communities in planning and decision-making processes in order to ensure the achievement of economic benefits from 
tourism is crucial for this type of DMO, oriented to the promotion of equitable business through marketing and product development assistance, supported by an assessment of socio-economic, cultural and environmental impacts.

The large number of stakeholders involved, the potential conflicts of interest and the different types of perceptions as well as knowledge coexisting within local communities can constitute obstacles for the efficiency of a DMO, as discussed by Morrison (2019). However, efficiency and value creation are also crucial for the existence and legitimacy of a DMO, as pointed out by Reinhold et al. (2018), when analysing DMOs from the point of view of their business models. The main DMO principles, according to the framework proposed in this work, are presented in the "Value Creation" column of Table 2. They are oriented towards specific interests of the companies operating in tourism businesses (and not towards the broader users of common resources), aiming at ensuring that their interests are taken into account when planning the utilisation of resources as well as marketing products and services. All these aspects, problems and limitations are taken into account in the framework model developed in the next Section.

\section{Conceptual framework for participatory tourism destination management}

Considering the concepts, concerns and guidelines presented and discussed in the previous Section, Table 2 integrates and synthesises the main principles proposed by each of these approaches, taking into account three key aspects for the implementation of a participatory process of tourism destination management: planning and management (including territorial resources as well as the products and services to be developed); monitoring impacts (socio-economic, cultural and ecological impacts); and stakeholder involvement (forms of participation of the different stakeholders in a destination). The blank spaces in the table emphasise the limitations (or "black holes") of each approach and the need to integrate different theoretical approaches.

The table includes contributions from different streams of literature: column 3 and column 4 refer to principles related to the management of cultural and natural resources, taking into account the guidelines proposed by ICOMOS (1999) and UNWTO (2003); column 5 refers to the recommendations proposed by UNWTO (2007) for the operationalisation of a DMO that integrates sustainable development principles into its mission; column 6 synthesises the main principles for the management of CPR inspired by the work of Ostrom $(2005,2008)$; columns 7 and 8 present the principles proposed by Moore, Rodger (2010) and Heenehan et al. (2015) for the management of ecological CPR in a context of tourism development. Column 8 integrates principles proposed by Reinhold et al. (2018) for the value added by a DMO.

Taking into account the concerns, proposals and limitations of these contributions, Table 3 represents our conceptual framework for a DMO oriented towards the sustainable development of a tourist destination through a community-based governance model, including the management of CPR. This framework reflects the need to integrate the principles from diverse theoretical perspectives into the diverse stages of action of a DMO (strategic planning, operational planning, management and monitoring), with varied levels of stakeholders' involvement and participation at each stage. This multi-level adaptive framework aims at creating an institutional arrangement combining effective participatory methods for planning and management of common resources utilization (including concerns with their preservation or different valuation of their importance within local communities, along with the importance of monitoring methods), with efficient mechanisms for the development and marketing of competitive tourism products and services that contribute to the sustainable development of a destination, generating socio-economic benefits for local communities.

We also assume that the focus on a long-term strategy for tourism competitiveness implies the definition of a "vision" (as an aspiration) and a mission (what is expected to be achieved and how it can be measured), as defined by Pike (2016), along with his distinction between "goals" (general qualitative statements) and "objectives" (strategic targets, possible to measure through quantitative indicators). Similarly, David (2016) suggests that planning sustainable tourism development implies the definition of a "common vision" 


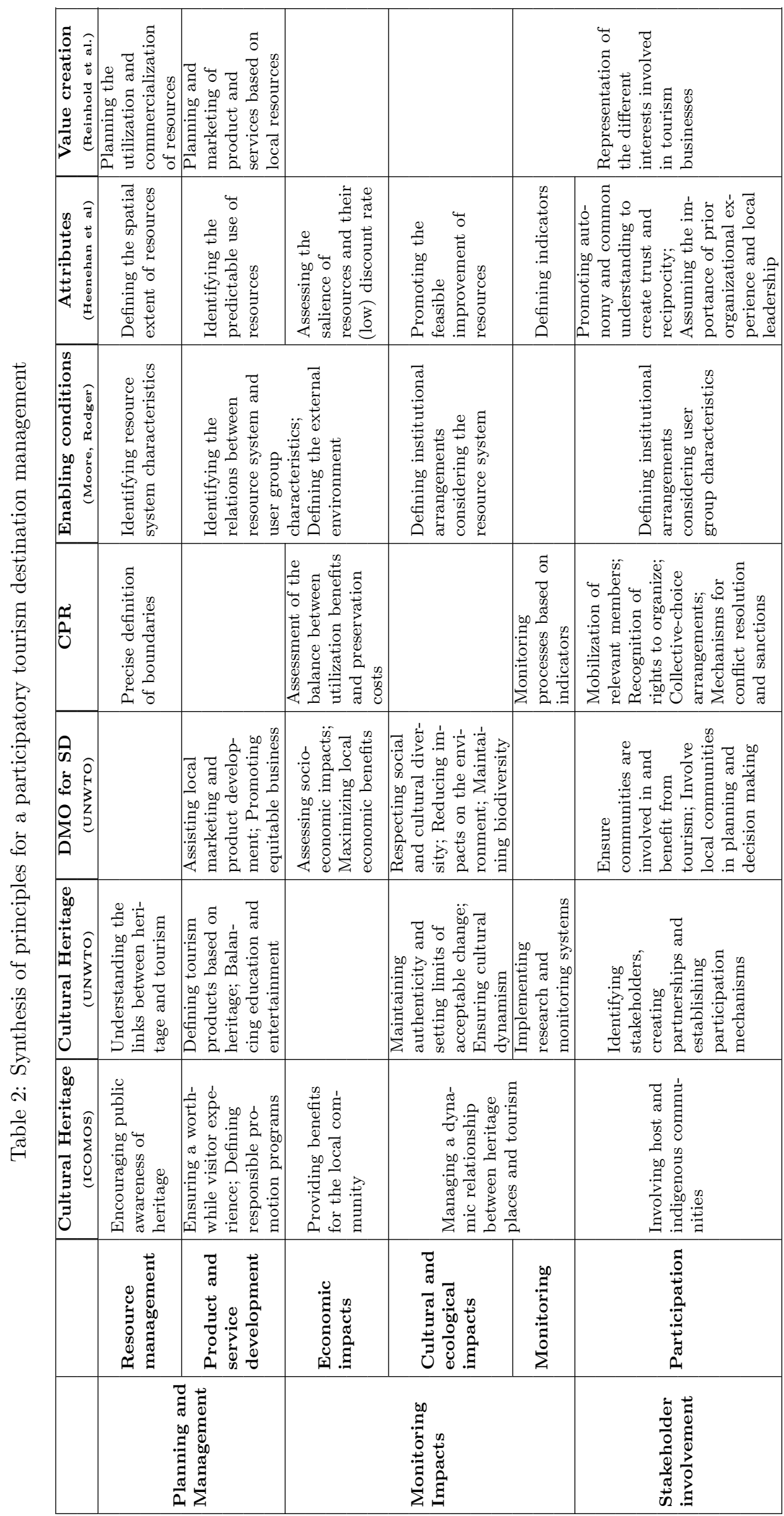


and a "mission statement" (how that vision can be achieved), the distinction between "goals" (development-driving forces) and "objectives" (specific and quantified targets to reach the goals), as well as the combination between long-term "strategies" (to achieve the objectives) and short-term "tactics" (for immediate achievements). UNWTO (2007) combines long-term vision goals and collectively defined short-term actions for a strategic approach to destination development.

Considering the large number of stakeholders involved in participatory destination management - along with the limitations related to the availability of information - we propose concerted involvement of all the stakeholders during the stages of "strategic planning" (definition of a long-term vision, goals, objectives and targets, with the related policy guidelines, regulations and indicators) and the "evaluation" (comparison between the achievements and the objectives). In both cases, it is crucial that institutions and stakeholders with specialised knowledge in specific fields (managers of ecosystems or cultural services and facilities, cultural agents, marketing strategists, transport planners, business developers, etc.) provide technical information to be shared among all stakeholders, integrated into a strategic plan and translated into quantifiable and measurable indicators for collective assessment. Depending on the size of the destination, the number of stakeholders involved and the funds available, advisory panels for specific topics or domains can be set up (Morrison 2019).

From the point of view of CPR management, it is also crucial that all the rules and conditions for their utilisation, preservation as well as the appropriation of benefits are considered during the phase of strategic planning, in order to reflect a consensual view from all the representatives of local communities. Moreover, these rules and conditions must be followed through the creation of a precise set of indicators, so that all the stakeholders can evaluate the situation of the CPR during the monitoring stage (and ideally, during the other two stages as well).

The other two stages relate to "operational planning" (integration of goals, objectives and targets of the destination into the actions of each involved stakeholder) and "management" (focused on the execution of specific tasks by each stakeholder), being mostly performed at the individual level. The DMO's role during this period mostly lies in coordinating, facilitating, communicating, and eventually contributing to the resolution of conflicts and the performance of specific tasks (marketing or provision of commercial services). DMO can also have an active role in the development and management of digital platforms integrating the diverse tourism services available at the destination.

Considering the importance of CPR for local communities and the need to guarantee an efficient performance of different organizational tasks (including timely decisions and flexible responses to a changing environment, market fluctuations or other occasional disturbances and opportunities), the creation of a specific "committee" (as defined by Morrison 2019) for a regular assessment of the eventual co-production, utilisation and preservation of CPR may be considered. This assessment must take into account the rules and indicators defined within the "Strategic Planning", but not implying collective decisions for the regular utilisation of those resources, as long as they are framed by the strategic guidelines. For other utilisations, however, a revision of the rules based on community consensus may be required.

A crucial aspect of this framework is the definition of objective and quantified indicators during the planning phase, in order to ensure the possibility of a collective assessment of strategic objectives. Following a holistic approach to sustainable development, these indicators should cover the ecological, cultural, social and economic dimensions of tourism dynamics, apart from the utilisation, preservation and appropriation of benefits related to CPR. For the ecological and cultural aspects, indicators related to carrying capacity, number of users, impacts on the degradation of resources or on their protection and valorisation should be considered, along with broader indicators related to pollution, $\mathrm{CO} 2$ emissions, biodiversity or cultural diversity. The assessment of social aspects may be based on indicators related to employment, salaries, labor relations, education, poverty, housing or social inequalities. Finally, economic impacts can be assessed on the basis of the number of visitors and overnight stays, expenditures from tourists at the destination, number of jobs and companies created and destroyed, as well as sectorial specialisation or 
Table 3: Tasks and stakeholders for participatory destination management organisation

\begin{tabular}{|c|c|c|c|c|}
\hline Stage & Strategic planning & Operational planning & Management & Monitoring \\
\hline Objective & Common vision & Action planning & Execution & $\begin{array}{l}\text { Performance } \\
\text { evaluation }\end{array}$ \\
\hline \multirow{6}{*}{ Tasks } & Mission & & & Assessment \\
\hline & Goals (driving forces) & Objectives (targets) & & Assessment \\
\hline & $\begin{array}{l}\text { Core products and } \\
\text { services }\end{array}$ & $\begin{array}{l}\text { Product and service } \\
\text { development; Plans } \\
\text { for education and } \\
\text { training; Plans to } \\
\text { support investment } \\
\text { and } \\
\text { entrepreneurship }\end{array}$ & $\begin{array}{l}\text { Selling products } \\
\text { and services; } \\
\text { Reservation } \\
\text { systems; } \\
\text { Information } \\
\text { desks; Support } \\
\text { services; ICT } \\
\text { applications; } \\
\text { Events }\end{array}$ & \\
\hline & $\begin{array}{l}\text { Limits (carrying } \\
\text { capacity) }\end{array}$ & Market research & $\begin{array}{l}\text { Brand manage- } \\
\text { ment; Pricing; } \\
\text { Promotional } \\
\text { campaigns; In- } \\
\text { coming services } \\
\text { (receiving tou- } \\
\text { rists) }\end{array}$ & \\
\hline & General impacts & Specific impacts & & Assessment \\
\hline & Global indicators & Detailed indicators & & Assessment \\
\hline \multicolumn{5}{|l|}{ Stakeholders } \\
\hline $\begin{array}{l}\text { Technical staff at } \\
\text { DMO }\end{array}$ & Technical support & Coordination & $\begin{array}{l}\text { Coordination; } \\
\text { Service provision }\end{array}$ & $\begin{array}{l}\text { Technical } \\
\text { support }\end{array}$ \\
\hline Private companies & \multirow{3}{*}{$\begin{array}{l}\text { Discussion } \\
\text { Consensus }\end{array}$} & Planning & Service provision & \multirow{3}{*}{$\begin{array}{l}\text { Assessment; } \\
\text { Strategic } \\
\text { (re)orientations }\end{array}$} \\
\hline Public institutions & & $\begin{array}{l}\text { Regulation and } \\
\text { infrastructures }\end{array}$ & Service provision & \\
\hline $\begin{array}{l}\text { Community } \\
\text { representatives }\end{array}$ & & & & \\
\hline
\end{tabular}

evolution of the GDP.

The lack of data and information availability at the destination level is an important obstacle to the implementation of an effective assessment and monitoring system. However, different international institutions have made important efforts to measure different aspects and impacts of tourism dynamics at different territorial levels, including the socioeconomic dimensions within Tourism Satellite Accounts (OECD 2000, United Nations 2010) or enlarging the scope of analysis in order to integrate other aspects of sustainable development (UNWTO 2004, European Commission 2006). UNWTO $(2016,2017)$ is currently developing a "statistical framework for sustainable tourism", aiming at offering guidelines and tools for this kind of assessment.

The integration of local knowledge from the different stakeholders involved into tourism activities appears as a crucial aspect for an effective participatory management process, but also for providing the technical information and data supporting the creation of an effective monitoring system (Hall 2019). Such an information system can benefit from the development of digital platforms, as pointed out by Sigala, Marinidis (2012). Similarly, Boes et al. (2016) claim that a smart destination does not rely only on the technological aspects of digitalisation, but mostly on its utilisation for the implementation of participatory processes of destination management. The next section illustrates the aforementioned principles and guidelines through a case-study in Japan. The main purpose is to discuss whether the conceptual model presented above can serve as a useful operational tool for participatory tourism planning and management in this type of rural destination.

\section{Tourism and commons in Kushiro-Akan (East Hokkaido, Japan)}

Tourism in the rural region of Kushiro-Akan is based on the natural and cultural features of the region, including hot springs, the authenticity of the Japanese onsen tradition, natural parks and other ecological sites, museums and other cultural as well as educational 
facilities (including the cultural heritage related to the indigenous Ainu communities). Apart from the traditional hospitality services (accommodation and restaurants), these resources can be broadly defined as CPR, thus justifying participatory management. The main characteristics of each of these resources are briefly described below, concluding with some observations on existing tourism management organisations.

Kushiro City has 169.000 inhabitants (March 2019), with a low density (124 persons per km2). 210 accommodation facilities (33 "conventional" hotels and 174 ryokans) with 7484 rooms (3760 in "conventional" hotels, with an average of 114 rooms per facility; and 3578 in ryokans, corresponding to 21 rooms per facility) were registered in 2015. According to Akan Tourism Association (2018), 609.000 tourists visited the area in 2017 (20\% being Japanese guests). Most foreign visitors came from Taiwan (50\%), China (20\%) and Hong Kong (9\%). Despite its relatively small size, Kushiro-Akan incorporates the main areas of 2 of the 6 national parks in Hokkaido: Kushiro-Shitsugen, comprising Japan's largest marsh, the Kushiro Marsh (designated a Ramsar site), a habitat for diverse flora and fauna (including the red-crowned crane, a National Special Natural Monument); and Akan-Mashu National Park, including the Akan (the mountainous areas around Lake Akan and Lake Onneto) and the Mashu (around the lakes Mashu and Kussharo) areas. The region has 10 natural and scenic spots classified as interesting for tourists, one zoo, one aquarium, eight museums and three other cultural facilities, along with one ski resort and three golf courses. Moreover, this area features the "Ainu village", where traditional aspects of the Hokkaido indigenous group's culture can be explored.

In a broad sense, the territorial resources that can be classified as CPR are: the hot springs supporting the supply of the Japanese bath tradition (onsen), a unique experience with potentially positive impacts on users' health and wellness; the natural (parks and other scenic elements) and cultural (museums and other facilities) resources accessible to the visitors for different types of activities; and the unique resources (traditional products, crafts, music, dance or lifestyles) related to the presence of Ainu communities.

\subsection{Onsen (hot springs)}

The onsen (traditional Japanese bath) is based on the water properties of the Japanese hot springs and is associated with wellness, relaxation or meditation activities. Although some springs flow in open spaces (with free public access), they are generally integrated into accommodation facilities (hotels, which may follow the traditional Japanese ryokan type of accommodation). As a compensation for the community, the Municipalities charge a tax (approximately $€ 1.2$ ) for each person using the bath. This tax is included in the accommodation cost (for hotel guests) or is paid as an entrance fee. Landowners require a permit from the prefectural government for the exploitation of the hot springs, based on an application evaluated by a screening committee. Quality controls based on national laws defining the thermal characteristics (chemical composition and temperature of the springs) are performed before the license is given and also during the exploitation phase.

The spatial extent of this resource is clearly delimited, while its quantity and quality are highly predictable. The privatisation of the resource through a license for its exploitation can potentially increase its protection, since there is a specific stakeholder responsible for its maintenance as well as a public institution controlling its quality and quantity. The community is then compensated for the privatisation of the resource through a municipal tax. However, part of the revenue obtained with this tax is invested in the creation and maintenance of tourism events and infrastructure, thus offering a new advantage for the hospitality companies.

This process is potentially conflictive within a community, for a particular entity (a hotel) can take advantage of the resource's privatisation. Whether the compensation paid to the local authorities is fair or not, once there is a direct negotiation and regulation with the City Council, it is no longer a matter of discussion within communities. The supply of accommodation services is as an externality to the exploitation and utilisation of these thermal waters, and hotels offering onsen services normally charge higher prices. Moreover, at least in the Kushiro-Akan destination, dinners are generally included in the accommodation cost, thus constraining the opportunities for the development of restaurant services in the area. In this sense, the private appropriation of the hot springs 
contributes to the achievement of a dominant position, not only in the provision of accommodation, but also in other tourism-related services. Thus, the achievement of positive results within the social dimensions of sustainable development (generating and spreading economic benefits for the local populations) clearly depends on the negotiation and implementation of appropriate processes of resource management.

\subsection{Natural and cultural resources}

The particular ecosystems of the region offer diverse opportunities for recreational and educational nature-based activities. These resources are clearly identified, delimitated and protected, being managed by public institutions which regulate their utilisation for commercial purposes. Activities undertaken in this area usually include boat trips (on the Akan Lake), bird watching and hiking. However, the number of visitors s activities in natural areas (below 2.000 per year) is extremely low in comparison with the number of users of ski resorts (more than 200.000 per year), which seem to be the most significant attraction of the region.

Apart from the boat trips on the Akan Lake (with boarding places located very close to accommodation facilities), these nature-based activities do not seem adequately integrated into the local tourism dynamics, with low level of service development and low economic impacts. In this sense, the current utilisation of the resources does not lead to any of the potentially negative implications (free-riding or lack of protection). Instead, it seems that their use can be widened in order to generate socio-economic benefits for the local communities. Clearly, transportation and mobility services, along with information for non-Japanese travellers could contribute to diversify the attractions and services currently enjoyed at the destination. Moreover, there is no available statistical information related to the utilisation of these ecological resources (jobs created, amount of revenue generated, etc.), implying that the potential socio-economic impacts of these tourism-related activities cannot be effectively assessed.

Similarly, the utilisation of local museums and cultural facilities for international tourists also seems far from its full potential. Despite the emphasis on education and recreation (mostly related to local ecosystems and cultural heritage) at the facilities and in services they provide, their integration into tourism dynamics (through the creation of routes, packages of services, etc.) is not properly addressed. Furthermore, the information available to non-Japanese travellers is insufficient. It appears that a larger involvement of the institutions in charge of these facilities and services within the local tourism management organisations would contribute to the diversification of tourism services in the area, as well as result in higher socio-economic benefits for the local community through job creation.

In the case of these common resources, a management process oriented towards sustainable development should include local communities in order to increase the potential economic benefits, create opportunities for small companies to develop new services (interpretation, guided tours, ICT, food and drinks, etc.), generate jobs (social dimension), and limit the use of sensitive resources (environmental aspects).

\subsection{Ainu traditional heritage}

The Ainu are the indigenous people who have lived mainly in the northern part of the Japanese archipelago before the arrival of Japanese inhabitants in the late 19th century. They have their own spoken language and distinctive culture. In the late 19th century, after the Meiji Restoration, Ezochi /Ainu Mosir was renamed "Hokkaido". The Meiji government had direct control over the region and promoted an institutional unification, introducing the modern land ownership system. Besides, a large scale of immigration from the main island of Japan and the so-called "cultural enlightment movement" (which banned practicing Ainu customs) were carried out. These measures inflicted decisive damage on all aspects of the Ainu culture and livelihoods, implying the assimilation of Ainu into the Japanese culture (Advisory Council for Future Ainu Policy 2009).

In April 2019, the Japanese government enacted a new law recognising the Ainu ethnic minority as indigenous people of Japan for the first time in history. This new law expands 
Table 4: Existing tourism management organisations in Kushiro-Akan

\begin{tabular}{|c|c|c|c|c|}
\hline Territorial level & Prefecture & \multicolumn{2}{|c|}{ Multi local } & Local \\
\hline Denomination & $\begin{array}{l}\text { Hokkaido Tourism } \\
\text { Organization }\end{array}$ & $\begin{array}{l}\text { Kushiro Tourism } \\
\text { \& Convention } \\
\text { Association }\end{array}$ & $\begin{array}{l}\text { The road to the } \\
\text { general Institute of } \\
\text { East Hokkaido } \\
\text { natural beauty } \\
\text { DMO }\end{array}$ & $\begin{array}{l}\text { Akan Tourism } \\
\text { Association \& } \\
\text { Community } \\
\text { Development } \\
\text { Organization }\end{array}$ \\
\hline $\begin{array}{l}\text { Related policy } \\
\text { institutions }\end{array}$ & $\begin{array}{l}\text { National Govern- } \\
\text { ment, Prefectural } \\
\text { Government }\end{array}$ & $\begin{array}{l}\text { City Councils } \\
\text { (Kushiro City and } \\
\text { Teshikaga Town) }\end{array}$ & $\begin{array}{l}\text { City Councils (6 } \\
\text { cities and } 9 \text { towns } \\
\text { including Kushiro } \\
\text { and Teshikaga) }\end{array}$ & City council \\
\hline Legal type & $\begin{array}{l}\text { Public interest } \\
\text { incorporated } \\
\text { association }\end{array}$ & \begin{tabular}{|l|} 
General \\
incorporated \\
association
\end{tabular} & $\begin{array}{l}\text { General } \\
\text { incorporated } \\
\text { association }\end{array}$ & $\begin{array}{l}\text { Incorporated } \\
\text { non-profit } \\
\text { organisation }\end{array}$ \\
\hline Mission and tasks & $\begin{array}{l}\text { Territorial and } \\
\text { sectorial planning } \\
\text { and coordination; } \\
\text { Tourism planning } \\
\text { and related } \\
\text { policies }\end{array}$ & $\begin{array}{l}\text { Promotion; } \\
\text { Surveys and } \\
\text { human resource } \\
\text { development; } \\
\text { Information } \\
\text { centers and shops }\end{array}$ & $\begin{array}{l}\text { Promotion \& } \\
\text { Marketing of } \\
\text { tourism; Tourism } \\
\text { planning }\end{array}$ & $\begin{array}{l}\text { Tourism planning; } \\
\text { Marketing; } \\
\text { Promotion }\end{array}$ \\
\hline Staff & 41 persons & 20 persons & 4 persons & 10 persons \\
\hline Representative & $\begin{array}{l}\text { Former President } \\
\text { of private company } \\
\text { (bank) }\end{array}$ & $\begin{array}{l}\text { President of } \\
\text { private company } \\
\text { (environmental } \\
\text { services) }\end{array}$ & $\begin{array}{l}\text { President of } \\
\text { private company } \\
\text { (hotel) }\end{array}$ & $\begin{array}{l}\text { President of } \\
\text { private company } \\
\text { (tourism) }\end{array}$ \\
\hline
\end{tabular}

measures to promote, not only the Ainu culture, but also related economic activities, including tourism. A national Ainu museum and park will open in 2020 in the Hokkaido town of Shiraoi, which is expected to be a national centre for the revitalisation of Ainu culture. Ahead of this project, the "Council for the Ainu culture excursion trail" was established in 2017, involving Ainu organisations as well as travel and advertisement agencies, aiming at the creation of a cultural route between Shiraoi and the satellite cities of Hakodate, Biratori, Sapporo, Asahikawa and Akan (the "Yukar Road"). Featuring one of the most famous tourist attractions related to Ainu culture since World War II (the Marimo festival, created in 1950), Akan is a leading player in this project. Akan is also home to an Ainu village since the late 1950s, where Ainu residents opened craftwork shops and studios, along with hosting traditional dance performances, integrating their culture into tourism circuits in Akan (Saito 1999). Though Akan became a popular tourist destination, the Ainu community is facing several remaining challenges, such as competing with the Ainu crafts made outside Hokkaido or an insufficient mobilisation of Ainu culture as a tourism resource (Akibe 2010). In 2018, the Akan Tourism Association set up and launched new projects for the integration of Ainu heritage into tourism dynamics, involving representatives of the Ainu communities as consulting members.

The local processes for the sustainable development of tourism should be geared towards the active participation of these communities in destination planning and management, as in countries with populations of similar characteristics, like New Zealand or Australia. Such an involvement would allow these communities to have a more active participation in the tourism industry through the production of traditional goods as well as the development of new cultural, educational and recreational services based on their heritage, thus contributing to the economic and social dimensions of sustainable development.

\subsection{Tourism-related organisations}

Table 4 presents the characteristics of the tourism-related organisations operating in Kushiro-Akan.

The Hokkaido Tourism Organization, including representatives from the National and Prefectural governments, is responsible for framing tourism dynamics within regional development strategies, taking national policies into account. With a smaller territorial scale, the Kushiro Tourism \& Convention Association involves the neighbouring municipalities of Kushiro City and Teshikaga Town, being responsible for promotional initiatives and 
the management of tourism information centres, along with human resource development and implementation of surveys. Another multi-local organisation, the "Road to East Hokkaido Natural Beauty", was established in 2018 to cover almost all of Eastern Hokkaido.

At the local level, the Akan Tourism Association \& Community Development Organization appears most suitable for the management of natural and cultural resources within tourism development processes (according to general objectives defined in table 1), along with the integration and participation of local stakeholders, including Ainu communities (assuming the structure, processes and tasks proposed in Table 3). The purpose of this brief analysis is to test whether and how this structure corresponds to the conceptual model we proposed.

The organisation has been created, promoted and financed by the City Council in partnership with a very small number of large companies of the tourism sector, officially aiming at community development. However, the strategic plan supporting its activity is mostly focused on short-term marketing actions (until 2020), rather than a long-term comprehensive approach to sustainable development (Akan Tourism Association 2018). Moreover, the quantified objectives presented and the indicators proposed for performance assessment are exclusively oriented towards the tourism business, not towards a broader perspective of community or sustainable development.

In terms of organisation, there is a strong hegemony of three major companies operating in the area (accommodation, transport and marketing), which allocate human resources for the performance of the technical tasks of the DMO, while taking full responsibility for the decision-making process. However, efforts to involve stakeholders related to the management of natural and cultural resources and the Ainu communities, through processes of consultancy aiming at the achievement of a general consensus, have been made. Questions related to the appropriation of benefits arising from the externalities created by the privatisation of hot springs (which are concentrated in very large accommodation companies) are not addressed by the DMO. Similarly, there is no participatory decision making related to establishing limits for the utilisation of resources or the discussion of potential negative ecological, cultural, social and economic impacts. The indigenous Ainu communities particularly lack representation in the decision-making processes, and their specific knowledge and cultural heritage are not effectively used for the creation of unique and differentiated tourism products in the region. Similarly, there are no companies owned or managed by members of the Ainu communities providing tourism products or services.

When comparing the local DMO with our conceptual proposal, crucial differences, relating to the type of local stakeholders' involvement, become evident: although all the relevant entities in the tourism sector are consulted during the planning process, the final decisions are made by a few large stakeholders, which are in charge of the development of the future vision and its translation into goals, along with the identification of core products, services and potential markets. This reflects the focus on marketing issues, aiming at the reinforcement of the destination's attractiveness, rather than a process of sustainable development with broader objectives and indicators.

\section{Conclusion}

By pointing out the problems and obstacles for the creation of a local DMO promoting a tourism destination's sustainable development while ensuring active participation of local stakeholders in the processes of planning, managing and monitoring tourism activities and CPR, our conceptual model proposes a large participatory process for the stages of strategic planning and monitoring, combined with decentralised operational planning and management. From the point of view of the management of the commons, such an organisation would imply the articulation of rules for the utilisation and appropriation of related benefits during the stage of strategic planning, implying the definition of a broad and precise set of indicators for collective monitoring. Moreover, a specific committee focused on CPR management could be assigned to monitor their utilisation during subsequent stages. The effectiveness of this type of structure depends on technical information to be provided by specialised experts in different fields in a way that it can be 
shared among all involved stakeholders. Specific information and indicators are required for the assessment of the undertaken strategies, which often poses a difficulty at the local level. The work currently undertaken by institutions like UNWTO (2016), to define a set of local indicators for sustainable tourism development, may help create and consolidate participatory process of local tourism development.

However, the implementation of a concrete DMO with these purposes and principles depends on the characteristics of each destination. Different types of resources determining attractiveness, diverse levels of tourism development and positions in the life cycle of the destinations, different traditions and grades of organisation of local communities, as well as the types of support from public institutions may impose different constraints and open different opportunities for such a participatory management process in each destination. In this sense, further research is required in order to evaluate how such a process can be implemented in each place. The amount and diversity of stakeholders to be involved, along with the need to ensure enough stable financial resources and a well-balanced decision-making structure constitute important difficulties for their implementation. On the other hand, the creation of other types of organisations, without political legitimacy to coordinate or plan tourism activities, would surely result in strong difficulties when mobilizing local stakeholders.

The exploratory application of our conceptual model to a specific destination highlights the potential advantages of such a participatory tourism management structure, while pointing out the differences regarding the existing DMO. In this case, the activities of the organisation are mostly dependent on the initiative of large private companies, with potential negative implications on the diversification of services based on endogenous resources. The privatisation of common resources that ensures their protection also promotes a concentration of benefits in a small number of large companies. Since the number of visitors to the most sensitive areas (like natural parks) is relatively low, there are not significant problems of overutilisation or degradation of resources. However, it is clear that the economic potentials of natural and cultural resources are not fully exploited. The involvement of the Ainu communities is particularly very limited. Moreover, the DMO under investigation does not specify broad objectives and indicators for the three pillars of sustainable development, focusing exclusively on marketing goals. Although most of the tasks proposed in our conceptual model are performed by this DMO (except the monitoring process, which is very limited), there is a very weak representation of local stakeholders, limited to three large (and complementary) companies. These companies also provide the technical staff to the organisation, assuming all the tasks, while the participation of other local stakeholders is only possible through consultation processes, without formal involvement in decision-making processes.

In our view, the structure and operational framework of the said DMO clearly exemplify the difficulties of implementing an organisation based on the conceptualisation presented in this work. However, it is also clear that crucial aspects related to the utilisation of common sensitive resources, distribution of benefits among local communities or, in a broad sense, the potential achievements related to the three pillars of sustainable development, are not sufficiently addressed by the existing tourism development strategies for the area. In fact, despite the recommendations from UNWTO (2007) most of the existing DMOs do not assume large forms of local stakeholders' representation, with different interests and motivations regarding tourism dynamics. In general terms, they involve a coalition of public authorities and private companies, with limited participation of representatives of other types of groups of interest within the local population. From our analysis, the critical factors for overcoming this problem are:

- identification of legitimate representatives of different interests;

- potential high number of representatives, implying difficulties in achieving consensual solutions;

- adequate power balance between the stakeholders involved;

- stable and adequate financial contributions, not leading to power imbalances; 
- possibility to share and understand different forms of knowledge;

- achievement of a common vision;

- definition of clear objectives, measures and indicators;

- definitions of clear rules and regulations;

- policy legitimacy and possibility of the decisions' enforcement;

- broad culture of participation;

- ability to generate efficient and timely decisions.

Clearly, the challenges raised by contemporary tourism dynamics and their implications for local resources and communities justify the integration of sustainable development goals and broad participatory processes involving local stakeholders into formal destination management organisations. However, it is not possible to achieve ths without significant challenges and obstacles, which may be different in each place, depending on local pathdependent processes of cultural, economic, institutional and political evolutions. Our work resulted in the design of an operational framework for the analysis and creation of such organisations in specific tourist destinations, taking their specific characteristics into account.

\section{Acknowledgement}

João Romão acknowledges grant number 20K12392, by the Japan Society for the Promotion of Science (Kakenhi - type C). Peter Nijkamp acknowledges grant number PN-III-P4-IDPCCF-2016-0166, by the Romanian Ministry of Research and Innovation (ReGrow).

\section{References}

Advisory Council for Future Ainu Policy (2009) Final report. Comprehensive Ainu Policy Office, Government of Japan, Tokyo

Agrawal A (2001) Common property institutions and sustainable governance of resources. World Development 29: 1649-1672. CrossRef.

Agrawal A (2003) Sustainable governance of common-pool resources: Context, methods, and politics. Annual Review of Anthropology 32: 243-262. CrossRef.

Akan Tourism Association (2018) Innovation for managing resources: Human and financial resources in Akan DMO. Akan Tourism Association, Akan, Japan

Akibe H (2010) Tourism and the Ainu. In: Executive Committee of Symposium on Northern Peoples (ed), Contemporary Society and Indigenous Culture: Consideration through the Tourism and Art, Volume 1. Hokkaido Museum of Northern People, Abashiri, Japan, 19-23

Bimonte S (2008) The "tragedy of tourism resources" as the outcome of a strategic game: A new analytical framework. Ecological Economics 67: 457-464. CrossRef.

Boes K, Buhalis D, Inversini A (2016) Smart tourism destinations: Ecosystems for tourism destination competitiveness. International Journal of Tourism Cities 2: 108124. CrossRef.

Bramwell B, Sharman A (1999) Collaboration in local tourism planning. Annals of Tourism Research 26: 392-415. CrossRef.

Briassoulis H (2002) Sustainable tourism and the question of commons. Annals of Tourism Research 29: 1065-1085. CrossRef. 
Briassoulis H (2015) Tourism and common pool resources. In: Hall CM, Gossling S, Scott D (eds), Routledge Handbook on Tourism Sustainability. Routledge, London

Buhalis D (1999) Limits of tourism development in peripheral destinations: Problems and challenges. Tourism Management 20: 183-185

Butler RW (1999) Sustainable tourism: A state-of-the-art review. Tourism Geographies 1: 7-25. CrossRef.

Chambers E (2009) From authenticity to significance: Tourism on the frontier of culture and place. Futures 41: 353-359. CrossRef.

Cohen E (1988) Authenticity and commoditization in tourism. Annals of Tourism Research 15: 371-386. CrossRef.

Colomb C, Navy J (2017) Protest and resistance in the tourist city. Routledge, London. CrossRef.

Coronado G (2014) Natural and cultural commons and the organisation of community tourism projects in Mexico. Journal of Iberian and Latin American Research 20: 229-244. CrossRef.

David LE (2016) Managing Sustainable Tourism (2nd ed.). Routledge, New York. CrossRef.

Dietz T, Ostrom E, Stern PC (2003) The struggle to govern the commons. Science 302: 1907-1912. CrossRef.

Douglas JA (2014) What's political ecology got to do with tourism? Tourism Geographies 16: 8-13. CrossRef.

Dragouni M, Fouseki K (2018) Drivers of community participation in heritage tourism planning: An empirical investigation. Journal of Heritage Tourism 13: 237-256. CrossRef.

European Commission (2006) Methodological work on measuring the sustainable development of tourism. European Commission, Luxembourg

Fusco Girard L, Nijkamp P (2009) Cultural tourism and sustainable local development. Ashgate, Aldershot. CrossRef.

Fyall A, Garrod B, Wang Y (2012) Destination collaboration: A critical review of theoretical approaches to a multi-dimensional phenomenon. Journal of Destination Marketing Management 1: 10-26. CrossRef.

Graburn N (1995) The past in the present in Japan: Nostalgia and neo-traditionalism in contemporary Japanese domestic tourism. In: Butler R, Pearce D (eds), Change in tourism people, places processes. Routledge, London, 47-70

Grafton RQ (2000) Governance of the commons: A role for the state? Land Economics 76: 504-517. CrossRef.

Hall CM (2019) Constructing sustainable tourism development: The 2030 agenda and the managerial ecology of sustainable tourism. Journal of Sustainable Tourism. CrossRef.

Hassan S (2000) Determinants of market competitiveness in an environmentally sustainable tourism industry. Journal of Travel Research 38: 239-245. CrossRef.

Heenehan H, Basurto X, Bejderb L, Tyne J, Higham JES, Johnston DW (2015) Using Ostrom's common-pool resource theory to build toward an integrated ecosystem-based sustainable cetacean tourism system in Hawai'i. Journal of Sustainable Tourism 23: 536-556. CrossRef. 
Holden A (2005) Achieving a sustainable relationship between common pool resources and tourism: The role of environmental ethics. Journal of Sustainable Tourism 13: 339-352. CrossRef.

ICOMOS - International Council on Monuments and Site (1999) International cultural tourism charter. ICOMOS, Paris

ICOMOS - International Council on Monuments and Site (2008a) The ICOMOS charter for the interpretation and presentation of cultural heritage sites. Ratified by the 16th general assembly of ICOMOS, Québec

ICOMOS - International Council on Monuments and Site (2008b) The ICOMOS charter on cultural routes. Ratified by the 16th general assembly of ICOMOS, Québec

Jamal T, Stronza A (2009) Collaboration theory and tourism practice in protected areas: Stakeholders, structuring and sustainability. Journal of Sustainable Tourism 17: 169-189. CrossRef.

Landorf C (2009) Managing for sustainable tourism: A review of six cultural world heritage sites. Journal of Sustainable Tourism 17: 53-70. CrossRef.

Mason P (2016) Tourism impacts, planning and management (3rd ed.). Routledge, London. CrossRef.

Mazanec J (2010) Managing the heterogeneity of city tourists. In: Manzanec J, Wöber K (eds), Analysing international city tourism. Springer, Berlin, 81-94

Meinecke EP (1929) The effect of excessive tourist travel on california redwood parks. California State Printing Office, Sacramento

Miller G, Twining-Ward L (2005) Monitoring for a sustainable tourism transition: The challenge of developing and using indicators. CABI, Oxfordshire

Moore SA, Rodger K (2010) Wildlife tourism as a common pool resource issue: Enabling conditions for sustainability governance. Journal of Sustainable Tourism 18: 831-844. CrossRef.

Morrison AM (2019) Marketing and Managing Tourism Destinations (2nd ed.). Routledge, New York. CrossRef.

Musgrave AR, Musgrave P (1973) Public Finance in Theory and Practice. McGraw-Hill, New York

Nahrath S, Bréthaut C (2016) Coordination between institutional resource regimes as a condition for sustainable management of alpine touristic resources. Revue de géographie alpine (104-3). CrossRef.

OECD - Organization of Economic Cooperation and Development (2000) Measuring the role of tourism in OECD economies: The OECD manual on tourism satellite accounts and employment. OECD Publishing, Paris

OECD - Organization of Economic Cooperation and Development (2009) The impact of culture on tourism. OECD Publishing, Paris

ORRRC - Outdoor Recreation Resources Review Commission (1962) Report of the Outdoor Recreation Resources Review Commission. ORRRC, Washington DC

Ostrom E (2005) Understanding institutional diversity. Princeton University Press, Princeton. CrossRef.

Ostrom E (2008) The challenge of common-pool resources. Environment 50: 8-21. CrossRef. 
Ostrom V, Ostrom E (1977) Public goods and public choices. In: Savas ES (ed), Alternatives for Delivering Public Services: Toward Improved Performance. Westview Press, Boulder, 7-49. CrossRef.

Pike S (2016) Destination Marketing Essentials. Routledge, London. CrossRef.

Pirotta E, Lusseau D (2015) Managing the wildlife tourism commons. Ecological Applications 25: 729-741. CrossRef.

Poria Y, Butler R, Airey D (2003) The core of heritage tourism. Annals of Tourism Research 30: 238-254. CrossRef.

Rasoolimanesh SM, Ramakrishna S, Hall CM, Esfandiar K, Seyfi S (2020) A systematic scoping review of sustainable tourism indicators in relation to the sustainable development goals. Journal of Sustainable Tourism. CrossRef.

Reinhold S, Beritelli P, Grünig R (2018) A business model typology for destination management organizations. Tourism Review 74: 1135-1152. CrossRef.

Romão J (2018) Tourism, Territory and Sustainable Development: Theoretical Foundations and Empirical Applications in Japan and Europe. Springer, Singapore. CrossRef.

Romão J, Machino K, Nijkamp P (2017) Assessment of wellness tourism development in Hokkaido: A multicriteria and strategic choice analysis. Asia-Pacific Journal of Regional Science 1: 265-290. CrossRef.

Romão J, Machino K, Nijkamp P (2018) Integrative diversification of wellness tourism services in rural areas - An operational framework model applied to east Hokkaido (Japan). Asia Pacific Journal of Tourism Research 23: 734-746. CrossRef.

Romão J, Neuts B, Nijkamp P, van Leeuwen ES (2015) Culture, product differentiation and market segmentation: A structural analysis of the motivation and satisfaction of tourists in Amsterdam. Tourism Economics 21: 455-474. CrossRef.

Saito R (1999) History of relationship between tourism in Akan National Park and Ainu culture by compiling the remarks from the travel guide magazines in Showa period (1926-1980s). Hokkaido Museum of Northern Peoples, Note on Research 8: 111-124

Scott AJ (2017) The constitution of the city. Palgrave Macmillan, Cham. CrossRef.

Seyfi S, Hall CM, Fagnoni E (2018) Managing world heritage site stakeholders: A grounded theory paradigm model approach. Journal of Heritage Tourism. CrossRef.

Sharpley R (2009) Tourism Development and the Environment: Beyond Sustainability? Earthscan, London. CrossRef.

Sigala M, Marinidis D (2012) E-democracy and web 2.0: A framework enabling DMOs to engage stakeholders in collaborative destination management. Tourism Analysis 17: $105-120$

Tolkach D, King B, Whitelaw PA (2016) Creating Australia's national landscapes: Issues of collaborative destination management. Journal of Destination Marketing $\&$ Management 5: 117-132

Torraco RJ (2005) Writing integrative literature reviews: Guidelines and examples. Human Resource Development Review 4: 356-367. CrossRef.

Tribe J (2008) Tourism: A critical business. Journal of Travel Research 46: 245-255. CrossRef.

UNESCO - United Nations Educational, Scientific and Cultural Organization (2013) Managing cultural world heritage. UNESCO, Paris 
United Nations (2010) Tourism Satellite Account: Recommended Methodological Framework. UN Department of Economic and Social Affairs, New York

UNWTO - World Tourism Organization (2003) Study on tourism and intangible cultural heritage. UNWTO, Madrid

UNWTO - World Tourism Organization (2004) Indicators of sustainable development for tourism destinations: A guidebook. UNWTO, Madrid

UNWTO - World Tourism Organization (2007) A practical guide to tourism destination management. UNWTO, Madrid

UNWTO - World Tourism Organization (2012) Global report on city tourism. UNWTO, Madrid

UNWTO - World Tourism Organization (2016) Measuring sustainable tourism (MST): Developing a statistical framework for sustainable tourism. UNWTO, Madrid

UNWTO - World Tourism Organization (2017) Manila call for action on measuring sustainable tourism. UNWTO, Manila

Wagar J (1964) The carrying capacity of wildlands for recreation forest science. Monograph No. 7. Society of American Foresters, Washington, DC

Waligo VM, Clarke J, Hawkins R (2013) Implementing sustainable tourism: A multistakeholder involvement management framework. Tourism Management 36: 342-353. CrossRef.

Weaver D (2011) Can sustainable tourism survive climate change? Journal of Sustainable Tourism 19: 5-15. CrossRef.

Williams P, Ponsford I (2009) Confronting tourism's environmental paradox: Transitioning for sustainable tourism. Futures 41: 396-404. CrossRef.

World Commission on Environment and Development (1987) Our common future. Oxford University Press, Oxford

cc) () (8) (C) 2021 by the authors. Licensee: REGION - The Journal of ERSA, European Regional Science Association, Louvain-la-Neuve, Belgium. This article is distributed under the terms and conditions of the Creative Commons Attribution, Non-Commercial (CC BY NC) license (http://creativecommons.org/licenses/by-nc/4.0/). 